\title{
Potential for Increasing Southern Highbush Blueberry Flavor Acceptance by Breeding for Major Volatile Components
}

\author{
Jessica L. Gilbert \\ Horticultural Sciences Department, University of Florida, 2211 Fifield Hall, \\ Gainesville, FL 32611
}

\author{
Michael L. Schwieterman \\ Graduate Program for Plant Molecular and Cellular Biology, Gainesville, \\ FL 32611
}

\author{
Thomas A. Colquhoun and David G. Clark \\ Department of Environmental Horticulture, University of Florida, \\ Gainesville, FL 32611
}

James W. Olmstead ${ }^{1}$

Horticultural Sciences Department, University of Florida, 2211 Fifield Hall, Gainesville, FL 32611

Additional index words. Vaccinium corymbosum, fruit quality, blueberry breeding, flavor

\begin{abstract}
Previously, when selecting for flavor in the University of Florida southern highbush blueberry (SHB, Vaccinium corymbosum L. hybrids) breeding program, sugar/ acid ratios and breeder preference were the only factors considered. A more precise method of evaluating flavor would include volatile compounds that may also contribute to the flavor experience. Therefore, volatile profiles of five SHB cultivars (Farthing, FL01-173, Scintilla, Star, and Sweetcrisp) were compared using gas chromatographymass spectrometry. All cultivars were harvested on four separate dates within the harvest season, and fruit from each cultivar were also harvested at four developmental stages on the first harvest date. Among the cultivars, soluble solids content and volatile production tended to increase with fruit maturity, whereas titratable acidity decreased. All volatile components were more variable than measures of sugars and acids during the harvest season. Many of the volatiles present varied significantly between harvest dates, resulting in significant genotype $\times$ environment interactions during the harvest season. A closer examination of linalool, trans-2-hexenol, trans-2-hexenal, hexanal, and 1-penten-3-ol, five volatile compounds commonly associated with blueberry flavor, showed cultivar, developmental stage, and harvest date differences for each volatile. 'Star' experienced the least variation through the harvest period.
\end{abstract}

The University of Florida (UF) blueberry breeding program has been developing blueberry cultivars adapted to the subtropical Florida climate for over 60 years. During this time, many uncultivated Vaccinium species native to Florida were used as sources of adaptive traits when crossed with cultivated northern highbush blueberries (Vaccinium corymbosum L.) (Lyrene, 2002, 2008). Many generations of recurrent selection were required before an adequate commercial phenotype was recovered as a result of the need

Received for publication 8 Feb. 2013. Accepted for publication 17 May 2013.

The University of Florida Institute for Plant Innovation thanks Straughn Farms for the use of plant material and the University of Florida Plant Molecular Breeding Initiative for funding.

${ }^{1}$ To whom reprint requests should be addressed; e-mailjwolmstead@ufl.edu. to select against undesirable traits such as high chill requirements, late bloom, long bloom to maturity period, and susceptibility to various diseases from the northern highbush parental lines. Linkage drag from the wild species included black fruit color, low vigor, small fruit size, and wet stem scar (Lyrene, 2002, 2005, 2008; Lyrene and Sherman, 1984; Sharpe and Darrow, 1959). The hybrids developed through these efforts are referred to as SHB cultivars (Lyrene, 2008).

In the past, selection for flavor in the UF breeding program was based on subjective breeder ratings and calculation of a sugar/ acid ratio (soluble solids content/titratable acidity). However, eating quality of blueberries has been shown to have a much higher correlation to flavor acceptability and blueberry-like flavor intensity as opposed to simple measures of sweetness, acidity, or sugar/acid ratios (Saftner et al., 2008). The inconsistent relationship between consumer acceptability scores and these easily measured components of fruit quality is not surprising, because the flavor experience from eating a blueberry also consists of sensory perception of volatile organic compounds (Tholl et al., 2006; Tieman et al., 2012; Vogel et al., 2010). For example, the addition of fruity or floral volatiles to tomato fruit puree has been shown to improve perception of taste (Baldwin et al., 2008 ), and 12 volatile compounds independently significant in accounting for flavor intensity and sweetness in tomato were identified (Tieman et al., 2012). However, it is not necessarily the total amount of the volatiles synthesized in each fruit that is important to flavor, but the presence of specific volatiles, sometimes even in small amounts (Tieman et al., 2012; Vogel et al., 2010). The contribution of an individual volatile to fruit aroma has commonly been measured using log odor thresholds, a concept that does not necessarily hold true when the volatile operates synergistically or antagonistically with the rest of the compounds in a fruit's chemical matrix (Bott and Chambers, 2006; Drake and Ceville, 2003; Tieman et al., 2012). For example, $\beta$-damascenone and phenylacetaldehyde, which have high odor unit values and therefore have often been reported as key tomato flavor volatiles, were not associated with tomato flavor intensity (Tieman et al., 2012). This underscores the importance of studying the human perception of flavor compounds within the actual biological system rather than on a compound-by-compound basis.

Among various Vaccinium species and blueberry cultivars, significant variation in number and quantity of volatile compounds has been reported. However, a subset is common throughout the existing blueberry literature, including trans-2-hexenol, trans-2-hexenal, linalool, $\alpha$-terpineol, geraniol, limonene, cis3-hexen-1-ol, nerol, 1-penten-3-ol, hexanal, and 1,8-cineole (Baloga et al., 1995; Du et al., 2011; Hirvi and Honkanen, 1983; Horvat and Senter, 1985; Parliament and Kolor, 1975), and can be considered typical blueberry aroma compounds. Minimal mixtures of these compounds that compose a blueberry-like aroma as evaluated by trained flavor panelists include trans-2-hexenal, trans-2-hexenol, linalool (Parliament and Kolor, 1975), and cis-3hexen-1-ol and geraniol (Horvat and Senter, 1985).

In an effort to more effectively prioritize traits for flavor improvement given limited breeding resources, we sought to measure the characteristics associated with the blueberryeating experience. Our objectives were to determine which volatiles SHB cultivars are capable of synthesizing and to elucidate how stable the levels of these compounds are throughout the fruiting period. We hypothesized that volatiles would accumulate in number and increase in amount with maturity and would likely experience fluctuation across the harvest season. This work was a necessary first step in the move toward biochemical analysis for selection of quality blueberry flavor. 


\section{Materials and Methods}

Blueberry samples. Southern highbush blueberries were collected from a UF grower-cooperator farm near Windsor, FL (lat. $29^{\circ} 41^{\prime} 18^{\prime \prime} \mathrm{N}$, long. 82 $12^{\circ} 40^{\prime \prime} \mathrm{W}, 35 \mathrm{~m}$ elevation). The predominant soil types at this location were Bonneau fine sand and Newnan sand. Plots were planted in 30- to $45-\mathrm{cm}$ high raised beds formed with pine bark-incorporated native soil and pine bark mulch on the top. Spacing in the plots was $3 \mathrm{~m}$ between rows and $\approx 0.8 \mathrm{~m}$ within rows. Average annual precipitation is $\approx 120 \mathrm{~cm}$ with only 30 to $40 \mathrm{~cm}$ precipitation during the bloom through harvest season (February to May). Supplemental irrigation was provided with two driplines per row. Standard Florida blueberry management practices (irrigation, fertilization, pest control, and pruning) were followed (Williamson et al., 2004, 2013). The cultivars investigated in this study were 'Farthing', 'Scintilla', 'Star', 'Sweetcrisp', and 'FL01-173' (commercially available as Meadowlark $^{\mathrm{TM}}$ ) (Fig. 1). These five cultivars are grown in significant acreage in Florida, have been subjectively rated as having varied flavor characteristics, and had all four developmental blueberry stages available on the plants on the first harvest date. Mature blue fruit samples of each genotype were hand-harvested on 19 Apr., 26 Apr., 3 May, and 10 May 2011, spanning the most profitable market window for commercial blueberry growers in Florida. After the research samples were harvested, the same plots were harvested by the grower-cooperator for commercial production. Thus, on each weekly harvest date, only fruit maturing in the previous week were present. On the first harvest date, fruit was picked at four developmental stages from each genotype: green, breaker, red, and blue (Fig. 2). A single row, $\approx 125 \mathrm{~m}$ long (160 individual plants), of each cultivar was selected at the beginning of the harvest season and a pooled sample of blueberries was harvested from the same row at each harvest date. Samples were transported on ice back to the laboratory, frozen, and stored at $-80{ }^{\circ} \mathrm{C}$ until processing for volatile collections.

Volatile collection and analysis. Before biochemical analyses, fruit samples were defrosted at $4{ }^{\circ} \mathrm{C}$ overnight. The fruit was then homogenized in a blender for $15 \mathrm{~s}$. Thirty-five grams of each sample were loaded in triplicate into thin-walled glass tubes attached to a dynamic headspace volatile collection system with a column containing HaySep Q 80-100 porous polymer adsorbent (Hayes Separations Inc., Bandera, TX) at the tube outlet to capture volatile organic compounds over a period of $2 \mathrm{~h}$. Volatiles were eluted from the column with $150 \mu \mathrm{L}$ methylene chloride spiked with $5 \mu \mathrm{L}$ of nonyl acetate as an elution standard.

Volatile quantification and identification. Elutions were run on an Agilent 7890A Series Gas Chromatograph Flame Ionization Detector (GC-FID) (Agilent Technologies, Santa Clara, CA). Volatiles were analyzed on a DB-5 column $(30 \mathrm{~m}$ length $\times 250 \mu \mathrm{m}$ diameter $\times$ $1 \mu \mathrm{m}$ film; Agilent J\&W Scientific, CA). The
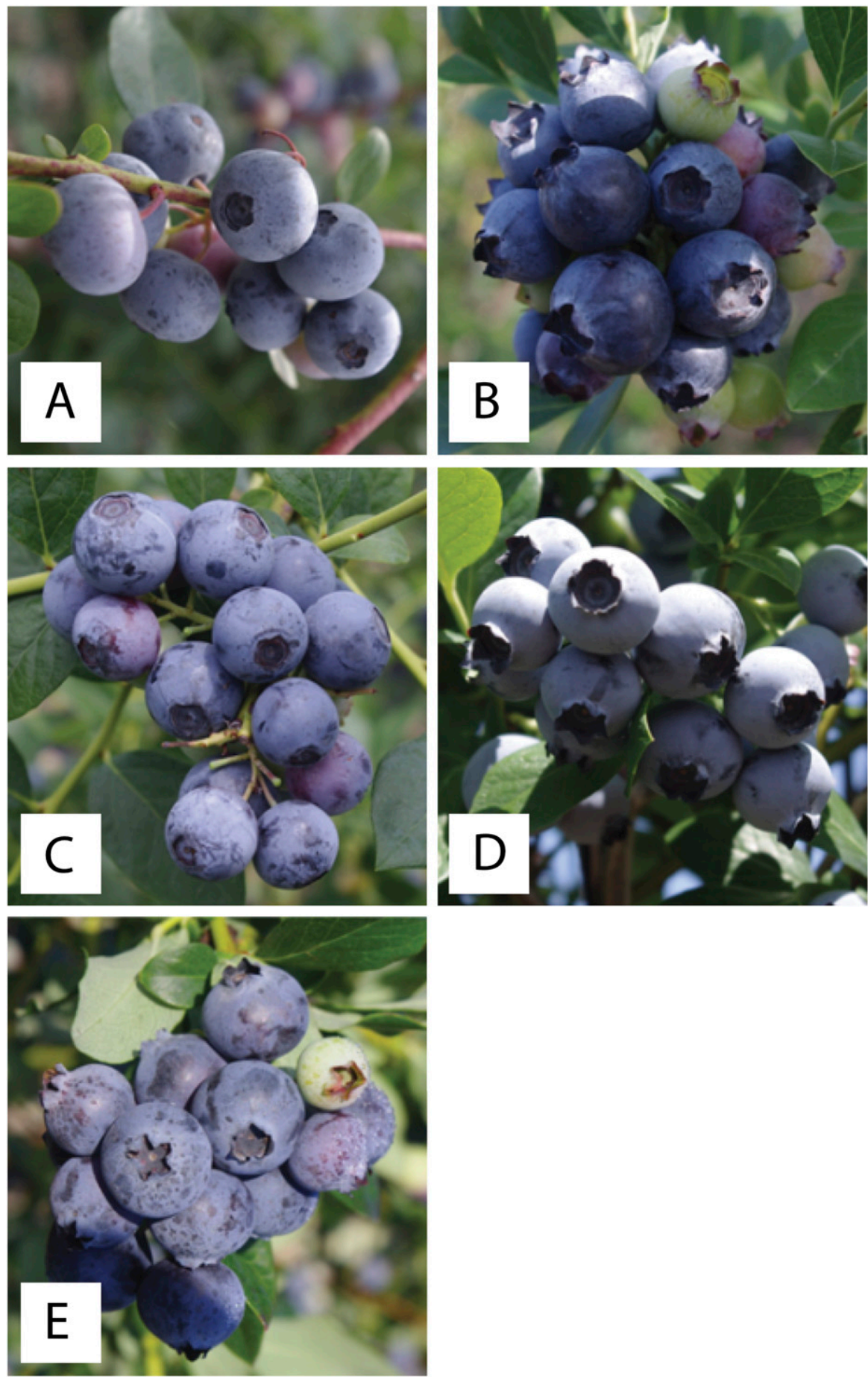

Fig. 1. Five southern highbush blueberry cultivars were harvested at four developmental stages and at four separate times during the harvest period for volatile analysis: (A) 'Scintilla', (B) 'Star', (C) 'Sweetcrisp', (D) 'FL01-173', and (E) 'Farthing'.

column flow rate was $3.99 \mathrm{~mL} \cdot \mathrm{min}^{-1}$. Initial oven temperature was $40{ }^{\circ} \mathrm{C}$ held for $0.5 \mathrm{~m}$, then increased at $5{ }^{\circ} \mathrm{C} \cdot \mathrm{min}^{-1}$ to $250{ }^{\circ} \mathrm{C}$, and held for 4 min at the final temperature. Peaks from the chromatography traces of compounds within a sample elution were integrated with Chemstation software (Agilent Technologies, Santa Clara, CA). Peak areas of detected volatiles were used to determine the mass of said compound within a sample through calculations that adjusted for nonyl acetate elution standard area and dilution curve as well as original biological sample mass (Dexter et al., 2007; Underwood et al., 2005), like so:

$$
\begin{aligned}
\text { Volatile Mass }_{\mathrm{s}}= & \left(\text { Volatile }_{\mathrm{pA}}\right) /\left(\mathrm{ES} \mathrm{pA}_{\mathrm{s}}\right) \\
& *\left(\mathrm{ES} \mathrm{pA}_{\mathrm{b}}\right) \\
& /\left(\mathrm{ES} \mathrm{Response} \mathrm{Factor}_{\mathrm{b}}\right) \\
& /(\text { Biological Sample Mass })
\end{aligned}
$$

where $\mathrm{pA}=$ peak area, $\mathrm{ES}=$ elution standard (nonyl acetate), $\mathrm{s}=$ sample $\mathrm{b}=$ batch, and the response factor was the slope of the equation of the dilution series. Gas chromatography-mass 


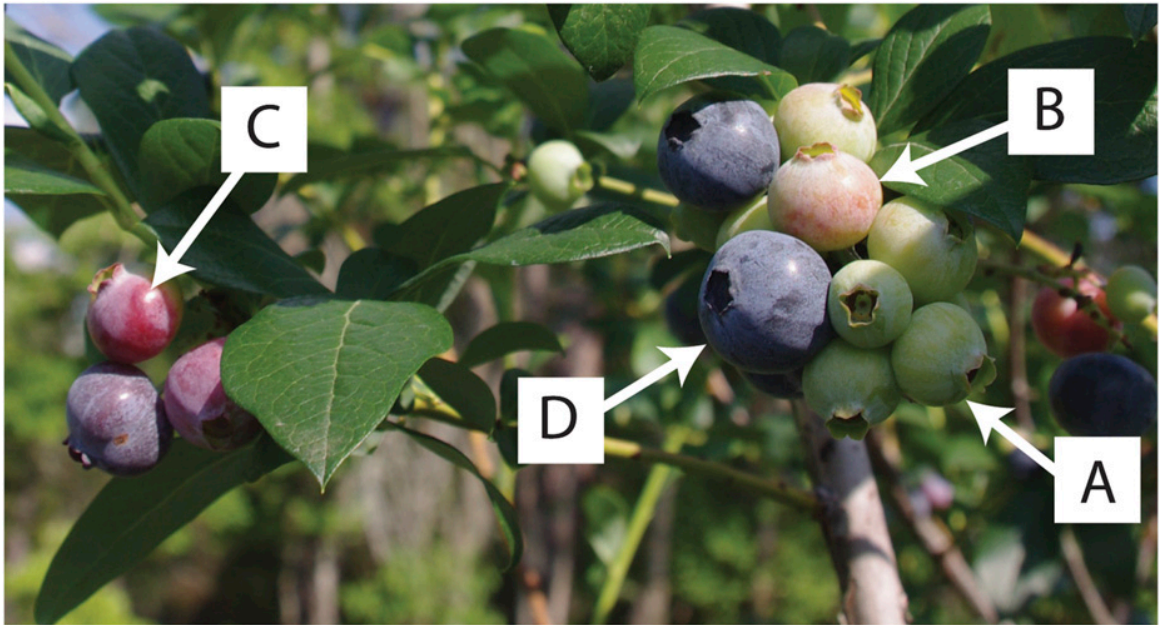

Fig. 2. Four developmental stages of each southern highbush blueberry cultivar were harvested for volatile analysis: (A) green, (B) breaker, (C) red, and (D) blue.

spectrometry (GC-MS) on an Agilent $6890 \mathrm{~N}$ GC in tandem with an Agilent $5975 \mathrm{MS}$ (Agilent Technologies) and coelution with known standards on GC-FID were used for compound identification. Both GCs were equipped with DB-5 columns.

$G C$ standards. Compounds for coelution were selected based on consensus within previous literature (Hirvi and Honkanen, 1983; Horvat and Senter, 1985; Parliament and Kolor, 1975) and volatiles detected by GCMS. These GC standards included: (-)-transcaryophyllene, (E)-2-hexen-1-ol acetate, (E)-2-hexen-1-ol, (E)-2-hexenal, (E)-2-pentenal, 1,2,3-trimethylbenzene, 1-hexanol, 1-octanol, 1-pentanol, 1-penten-3-ol, 1R-+-alpha-pinene, 2-heptanone, 2-methyl butanal, 2-methyl-1butanol, 2-pentanone, 2-phenethyl acetate, 2-phenylethanol, 6-methyl-2-hepten-2-one, aterpinene, a-terpineol, B-damascone, benzaldehyde, benzyl acetate, benzyl alcohol, benzyl benzoate, B-ionone, butyl acetate, cis-3-hexen1-ol, citronellyl acetate, cyclohexane, Dlimonene, eucalyptol, eugenol, geraniol, geranyl acetate, hexanal, isoeugenol, linalool, methyl benzoate, methyl salicylate, nerol, phenethyl benzoate, phenylacetaldehyde, terpineol, terpinolene, toluene, and nonyl acetate. Methylene chloride was used as a solvent.

Sugar and acid measurements. Remaining blended blueberry samples from the volatile collection step were immediately frozen at $-80{ }^{\circ} \mathrm{C}$ for sugar and acid quantifications. When sugar and acid measurements were to take place, the samples were defrosted overnight at $4{ }^{\circ} \mathrm{C}$ and then allowed to rise to room temperature for $2 \mathrm{~h}$. Fifteen milliliters of fruit puree were centrifuged at $15,000 \mathrm{rpm}$ for $25 \mathrm{~min}$ to obtain $10 \mathrm{~mL}$ of juice. Total soluble sugar content $(\% \mathrm{SS})$ was measured using a pocket refractometer (Atago U.S.A, Inc., Bellevue, WA) and $300 \mu \mathrm{L}$ blueberry juice. Six milliliters of juice was used to measure citric acid equivalent (\%TA) using an automatic titrator (Mettler Toledo Inc., Columbus, $\mathrm{OH})$.

Statistical analysis. Volatile data analyses were performed in JMP 8.0 (SAS Institute,
Cary, NC). Mean separation of volatile differences was by the Tukey-Kramer method.

The standard least squares regression model used for the analysis of $i$ genotype in $j$ environment was

$$
\mathrm{Y}_{\mathrm{ij}}=\mu+\mathrm{G}_{\mathrm{i}}+\mathrm{E}_{\mathrm{j}}+(\mathrm{G} \times \mathrm{E})_{\mathrm{ij}}+\varepsilon_{\mathrm{ij}}
$$

where $\mathrm{Y}=$ volatile response with population mean $\mu ; \mathrm{G}=$ genotypic effect; $\mathrm{E}=$ environmental effect, $\mathrm{G} \times \mathrm{E}=$ genotype $\times$ environment interaction effect; and $\varepsilon=$ residual effects. Genotype, environment, and genotype $\times$ environment were considered fixed factors (Cebolla-Cornejo et al., 2011). The model was validated by applying it to the nonyl acetate experimental standard, which showed no significant effects for $\mathrm{G}$ or $\mathrm{G} \times \mathrm{E}$. Significant effects for E exist because of expected experimental variation that occurred between volatile elutions of the different harvests.

An estimate of variability for each volatile within a genotype across harvests was calculated as the CV (Cebolla-Cornejo et al., 2011).

\section{Results}

Sugars and acids. SS and TA were measured across fruit development and at four points during the harvest season. There was an increase in sugar-to-acid ratios (SS/TA) as fruit matured from green to blue in all cultivars as a result of an increase in SS and decrease in TA (Fig. 3). There was a tendency for $\mathrm{SS} / \mathrm{TA}$ to continue to increase in mature fruit over the course of the harvest. SS/ TA measurements of 'Star' and 'Farthing' peaked on the third harvest, whereas SS/TA of the other three cultivars peaked on the fourth harvest (Fig. 3). To estimate the variability of sugars and acids across the harvest, the $\mathrm{CV}$ was calculated for the measurements within each genotype (Table 1). 'Sweetcrisp' and 'Farthing' had the lowest CVs for SS, TA, and SS/TA. 'Star' had the highest $\mathrm{CV}$ for SS and 'FL01-173' had the highest $\mathrm{CV}$ for $\mathrm{TA}$, and both had comparably large cVs for SS/TA.
Changes in volatiles during fruit development. We sought to profile the changes in volatiles through blueberry development, and volatiles reproducibly detected in developing fruit are shown in Supplemental Table 1. The general profile was an increase in total volatiles in blueberry samples as fruit progressed in maturity from green to blue (Fig. 4; Supplemental Table 1). 'Scintilla' had the greatest increase in total volatiles over development, with a 4-fold increase, followed by 'Sweetcrisp' with a 3-fold increase. 'Star' showed an approximate 2-fold increase in total volatiles over the developmental period, although the total volatile amount in 'FL01173' was far lower than 'Star'. 'Farthing' and 'FL01-173' showed no significant change in total volatiles, which remained low in the four developmental volatile measurements.

The same upward profile observed in total volatiles was evident in the accumulation of four of the five compounds examined in detail in this study (Fig. 5), each of which have previously been determined to be critical components of blueberry flavor quality (Horvat and Senter, 1985; Parliament and Kolor, 1975). Measurements of 1-penten-3-ol accumulation through development were unreliable as noted by the large error bars. Compared with the other three cultivars, 'FL01-173' and 'Farthing' had the smallest increases in hexanal, trans-2-hexenal, and trans-2-hexenol. 'Sweetcrisp' had the largest amount of trans-2-hexenol, and 'Scintilla' accumulated the most hexanal and trans-2hexenal before fruit maturity. Linalool accumulation was a sudden event that occurred in the mature blue stage. In going from red to blue, 'FL01-173' experienced a 3-fold increase in linalool and 'Sweetcrisp' showed a 20-fold increase. Changes in linalool accumulation from green to blue developmental stages ranged from insignificant in 'Scintilla' to a 77-fold increase in 'FL01-173'.

Changes in volatiles during the fruit harvest period. To determine the extent of variability in volatiles within a single cultivar over the course of the fruiting period, mature blue fruit were harvested at four successive dates. Total volatiles were stable throughout the 4-week harvest period for 'Star' and 'Sweetcrisp' (Fig. 4). Although 'Farthing' and 'FL01-173' initially lagged behind 'Sweetcrisp', 'Star', and 'Scintilla' in total volatiles, the two cultivars attained comparable volatile levels by the second harvest date. Within the season, the pattern of volatile accumulation varied. 'Scintilla' fruit experienced a decrease in total volatiles at the fourth harvest date, whereas 'Farthing,' fruit showed increases. Aside from the initial harvest point, total volatile content of 'FL01-173' fruit was relatively stable during the harvest period.

Similar variation was apparent in the production of individual volatile compounds (Fig. 6) that are commonly associated with blueberry flavor (Horvat and Senter, 1985; Parliament and Kolor, 1975). The profile of 1-penten-3-ol was relatively stable in 'Farthing', 'FL01-173', and 'Sweetcrisp'. However, 

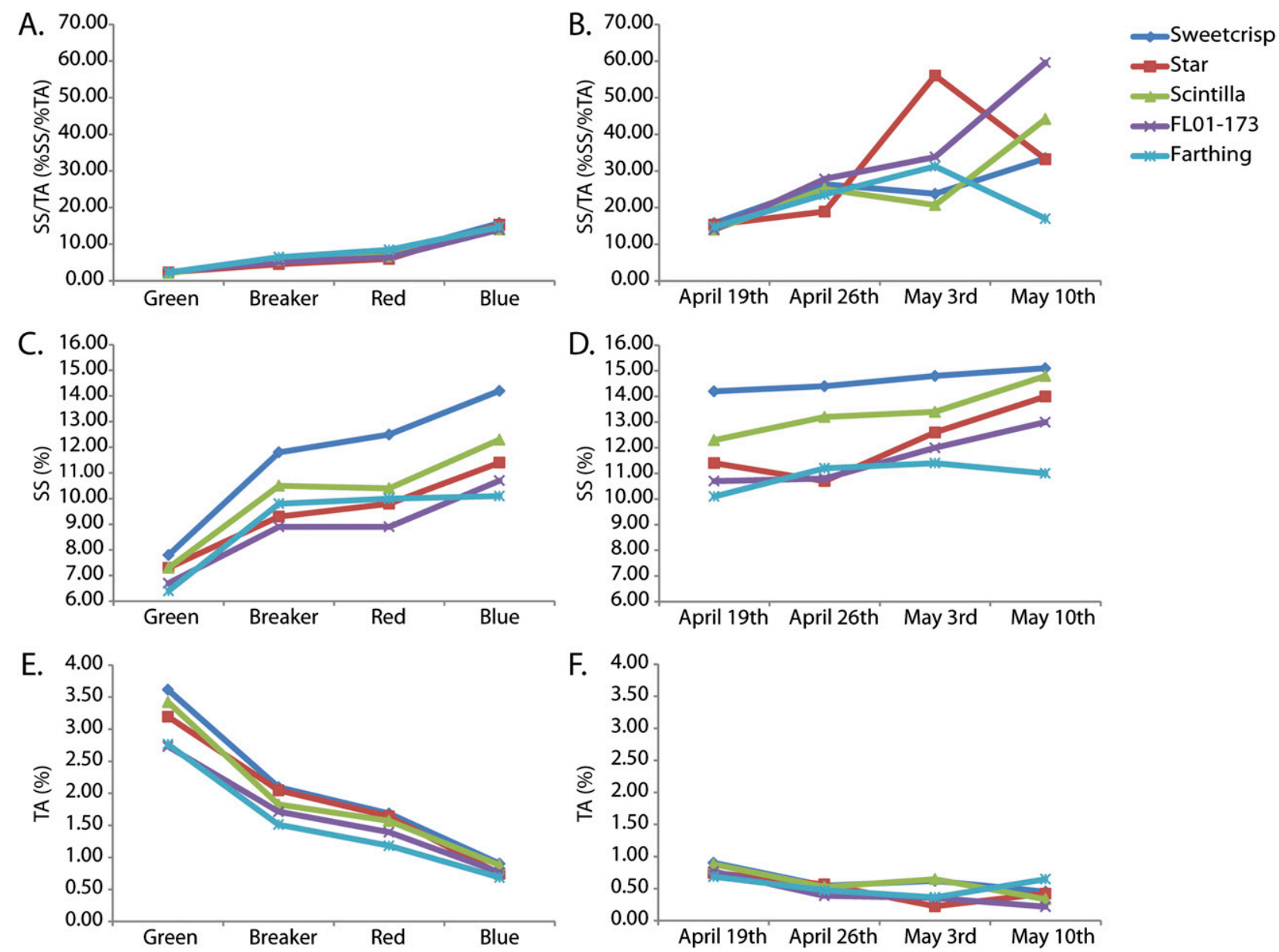

Fig. 3. Comparison of soluble solids/titratable acidity ratios (\%SS/\%TA) of five southern highbush blueberry cultivars (A) at four developmental stages: green, breaker, red, and blue, and (B) mature blue fruit at four points during the 2011 harvest season. Soluble solids and titratable acidity measures for both experiments are also shown $(\mathbf{C}-\mathbf{F})$.

Table 1. CV calculated for soluble solids (SS), titratable acidity (TA), and SS/TA measured at four harvest dates from five southern highbush blueberry genotypes ('Farthing', 'FL01-173', 'Scintilla', 'Star', and 'Sweetcrisp').

\begin{tabular}{lrcr}
\hline & \multicolumn{3}{c}{ CV } \\
\cline { 2 - 4 } Cultivar & \multicolumn{1}{c}{ SS } & TA & SS/TA \\
\hline Farthing & 5.25 & 28.53 & 34.36 \\
FL01-173 & 9.38 & 54.66 & 56.50 \\
Scintilla & 7.70 & 38.49 & 49.88 \\
Star & 11.89 & 45.36 & 59.87 \\
Sweetcrisp & 2.76 & 30.64 & 29.44 \\
\hline
\end{tabular}

production decreased in 'Scintilla' and varied significantly by harvest date in 'Star'. Overall, the content of trans-2-hexanal and hexanal increased in 'Farthing' and 'FL01-173', but if the extremely low values for the first harvest date are not considered, the contents of these two volatiles were relatively similar for both cultivars during the rest of the season. The large increases in total volatiles by 'Farthing' and 'FL01-173' on the second harvest appeared to result largely from increases in hexanal and trans-2-hexenal amounts (Fig. 6; Supplemental Table 2). Hexanal was stable in 'Sweetcrisp' and 'Star' but decreased in 'Scintilla' on the last harvest date. Trans-2-hexenal was also stable in 'Sweetcrisp' as well as 'Scintilla' but decreased at the third harvest in 'Star'. 'FL01-173' accumulated 2 to 3 -fold more linalool than the other four genotypes. As the harvest season progressed, linalool remained relatively stable among these other genotypes with a significant increase on the fourth harvest date. Trans-2hexenol showed significant fluctuations at every harvest date in 'Sweetcrisp', whereas 'Farthing', 'FL01-173', and 'Star' showed increases with successive harvest dates. 'Scintilla' initially decreased in trans-2-hexenol content but by the final harvest date had regained similar levels as the beginning of the season.

To quantify the variation over the harvests within each genotype, we calculated the $\mathrm{CV}$ for the five volatiles examined in this article in Table 2, similar to Cebolla-Cornejo et al. (2011) for tomato volatiles. Cvs for these selected volatiles indicated that 'Star' experienced the least seasonal variation overall, whereas 'Scintilla' experienced the most. Again, 1-penten-3-ol had the greatest variation over the course of the season.

Also of interest were the individual effects of genotype $(G)$ and environment $(E)$ on volatile production. In addition to individual effects, there is often an interaction effect between genotype and environment $(\mathrm{G} \times \mathrm{E})$ that cannot be accounted for by these two variables independently (Moore et al., 2002). All the volatiles detected in mature blueberry fruit throughout the harvest period and their effects of $\mathrm{G}, \mathrm{E}$, and $\mathrm{G} \times \mathrm{E}$ as indicated by a fixed-effect regression model are shown in Table 3. In this case, E represents the changes in conditions during the course of a harvest season, including such variables as temperature, precipitation, cropload, and irrigation. Certain volatiles such as 2-methyl butanal and 4-methyl-2-pentanone experienced exclusively E effects. In all cases other than toluene and 2-octane, a G effect also occurred in conjunction with $\mathrm{E}$ effects. In an unusual occurrence, $p$-xylene variation was the result of $G$ and $G \times E$, but was not significantly affected by $E$ in this study.

\section{Discussion}

Among breeding priorities, fruit flavor is commonly regarded as the most difficult trait to select for improvement. Although flavor is a complex trait, relatively simple measurements have been used in an attempt to quantify flavor differences. For example, SSs are a commonly used measure of sweetness in blueberry fruit. This measure of sweetness is commonly paired with TA to calculate an SS/TA ratio. Beaudry (1992) 
Total volatiles over fruit development

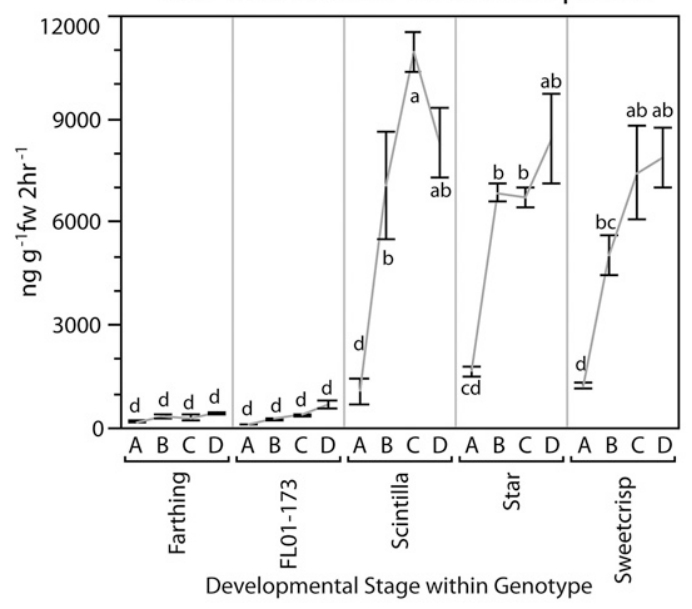

\begin{tabular}{|ll|}
\hline Key & 1:19 April \\
A: Green & 2:26 April \\
B: Breaker & 3:3 May \\
C: Red & $4: 10$ May \\
D: Blue & \\
\hline
\end{tabular}

Total volatiles over fruiting season

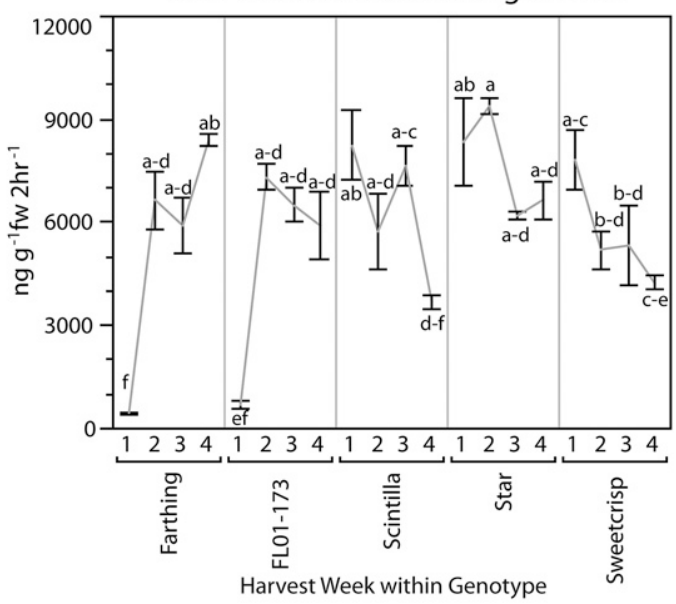

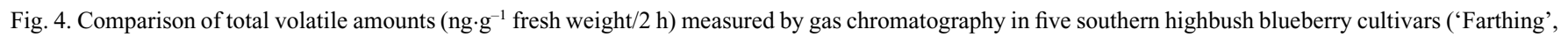
'FL01-173', 'Scintilla', 'Star', 'Sweetcrisp') at four developmental stages: green (A), breaker (B), red (C), blue (D), and mature blue fruit harvested at four points in the 2011 harvest period: 19 Apr. (1), 26 Apr. (2), 3 May (3), and 10 May (4). Each data point indicates the mean and standard error of three replications. Mean separations (Tukey-Kramer) are denoted by lower-case letters.

proposed that the acceptable range of SS/TA in blueberry was between 14 and 33 . The difficulty in applying these measures to breeding selection for flavor was illustrated by Saftner et al. (2008), in which two cultivars that fell outside of the acceptable range in the SS/TA calculation had significantly different flavor acceptability scores in consumer ratings. The SS/TA ratio for the cultivars in our study generally increased as the season progressed and ranged from 14 to 60. 'Star', 'Scintilla', and 'FL01-173' were outside this range of acceptability on at least one harvest date (Fig. 3). Given that flavor is a complex trait with many different variables contributing to consumer preference, the question becomes: with finite resources available to a breeding program, to what extent should the focus be on improving flavor? To identify potential breeding targets for flavor, we measured flavor components of five SHB genotypes throughout a harvest season and assayed the variation resulting from $\mathrm{G}, \mathrm{E}$, and $\mathrm{G} \times \mathrm{E}$. Because overall eating quality of blueberries has been most highly correlated with flavor acceptability and blueberry-like flavor intensity in consumer panels (Saftner et al., 2008), it was pertinent to measure not only variability of sugars and acids, but also the consistency of volatile compounds.

Variation in flavor-related characteristics among blueberry genotypes has previously been reported. Total SS and TA vary among Vaccinium species, cultivars, and harvest seasons (Ballington et al., 1984; Galletta et al., 1971; Saftner et al., 2008). Similarly, volatile levels have been shown to vary among Vaccinium species, genotypes, locations, general seasonal effects, and storage conditions (Almenar et al., 2010; Baloga et al., 1995; Du et al., 2011; Mattheis and Fellman, 1999). Among these characteristics, it is not yet clear what the extent of variation in volatiles during stages of fruit development and at multiple harvest dates within a season would be. Selecting for fruit that minimize $G \times E$ interactions for flavor will likely be important in generating cultivars with a stable flavor profile. Thus, we analyzed the variation of flavor components in five SHB genotypes at different developmental stages and within a single harvest season.

Woodruff et al. (1960) conducted a thorough analysis of blueberry organic composition through berry development. In agreement with the study presented here, they showed that the percentage of total sugars in blueberries increased for $9 \mathrm{~d}$ after color change and then leveled off and that TA decreases with fruit maturation (Fig. 3; Woodruff et al., 1960). Ballinger et al. (1963) and Kushman and Ballinger (1968) found that increases in blueberry cropload decreased sugar levels and had no effect on acidity. Over the course of the fruiting season, cropload is decreased through harvests, resulting in an increase in SS visible in Figure 3D.

Blueberries of five cultivars were harvested on $1 \mathrm{~d}$ at four stages of development: green, breaker, red, and blue (Fig. 2). Ripe blueberries were then harvested once a week for the next 3 weeks. Volatile profiles for compounds previously determined to be most critical to blueberry flavor quality, including linalool, trans-2-hexenol, trans-2-hexenal, hexanal, and 1-penten-3-ol, were analyzed in detail in these experiments, although all compounds detected were recorded (Supplemental Table 1) (Du et al., 2011; Hirvi and Honkanen,
1983; Horvat and Senter, 1985; Parliament and Kolor, 1975). Odor and flavor descriptors of volatiles are limited in that they may change with varied concentration within a sample and when in mixtures with other volatiles (Hongsoongnern and Chambers, 2008). However, linalool has often been cited as characteristic of blueberry aroma in previous literature (Du et al., 2011; Hirvi and Honkanen, 1983; Horvat and Senter, 1985; Parliament and Kolor, 1975) and is associated with a floral, fruity, citrus flavor. Trans-2-hexenol has been linked to green-viney, sweet, and pungent characters (Hongsoongnern and Chambers, 2008). Trans-2-hexenal has been described as fresh, leafy green, floral, sweet, and pungent, and 1-penten-3-ol has green-grassy and musty/earthy qualities (Hongsoongnern and Chambers, 2008). How these compounds actually interact within the biological system of a blueberry and their synergistic or antagonistic effects on the human sensory perception of flavor is a matter for further research.

As expected, total volatiles (Fig. 4) showed dramatic increases as ripening progressed (Horvat and Senter, 1985; Zhang et al., 2010). The six volatile compounds that have been associated with blueberry fruit flavor quality also increased as fruit matured (Fig. 5). When fruit is commercially harvested at an immature stage, many of these compounds could be produced at rates too low to achieve characteristic blueberry flavor (Mattheis and Fellman, 1999). Like in Du et al. (2011), trans-2-hexenal was the dominant compound in all fruit samples, making aldehydes the largest category of volatiles in these five cultivars of SHB. The profiles of total volatiles (Fig. 4) and trans-2-hexenal (Figs. 5 and 6) curves are shared. 

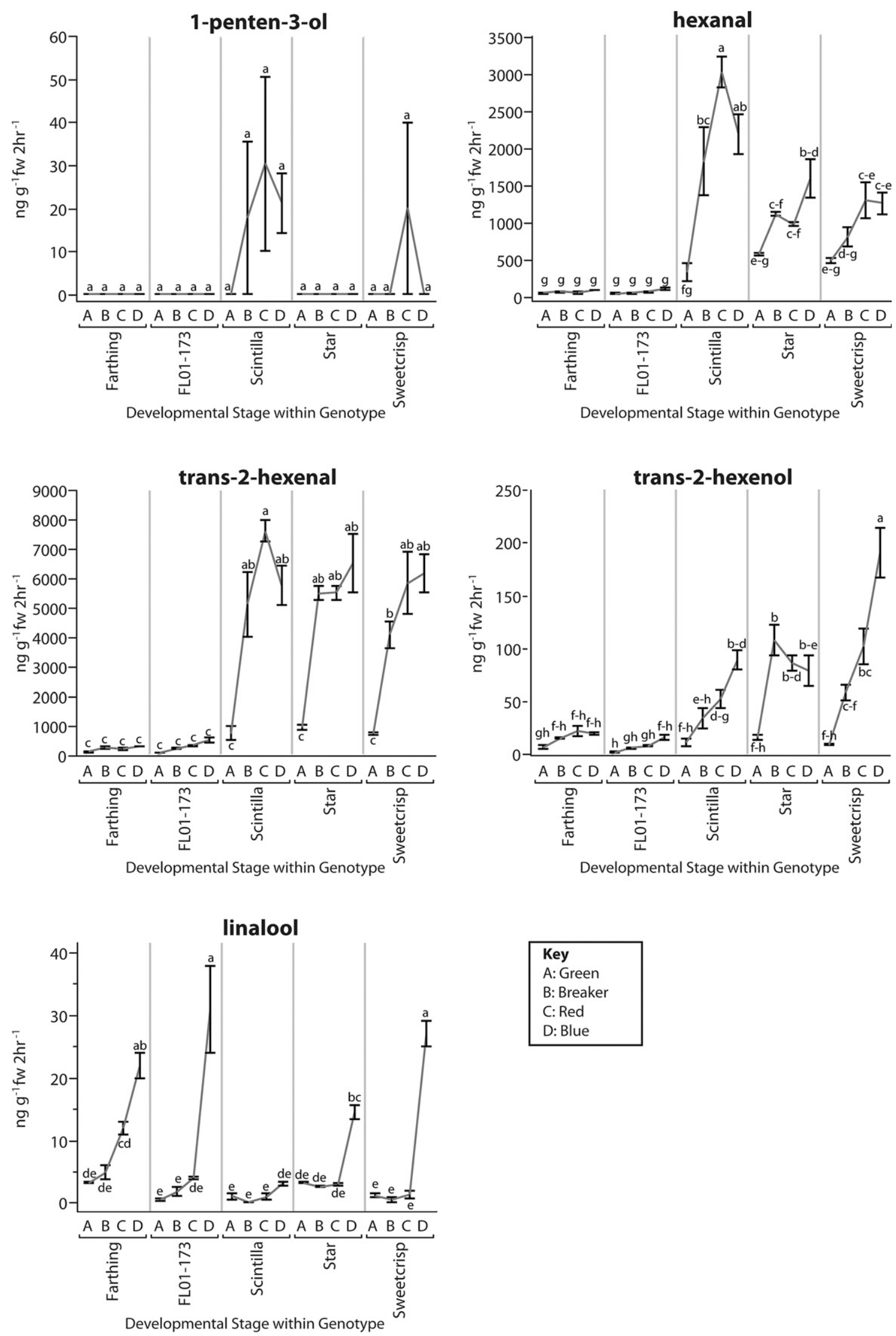

Fig. 5. Comparison of 1-penten-3-ol, hexanal, trans-2-hexenal, trans-2-hexenol, and linalool volatile profiles of five southern highbush blueberry cultivars collected at different stages of development. Each graph shows the amount of individual volatile compounds (ng.g ${ }^{-1}$ fresh weight $/ 2 \mathrm{~h}$ ) detected in 'Farthing', 'FL01-173', 'Scintilla', 'Star', and 'Sweetcrisp' at four different stages of fruit maturity: green (A), breaker (B), red (C), and blue (D). Volatile names are suggested based on gas chromatography coelution of chemical standards in conjunction with mass spectrometry. Each data point indicates the mean and sE of three replications. Mean separations (Tukey-Kramer) are denoted by lower-case letters. 

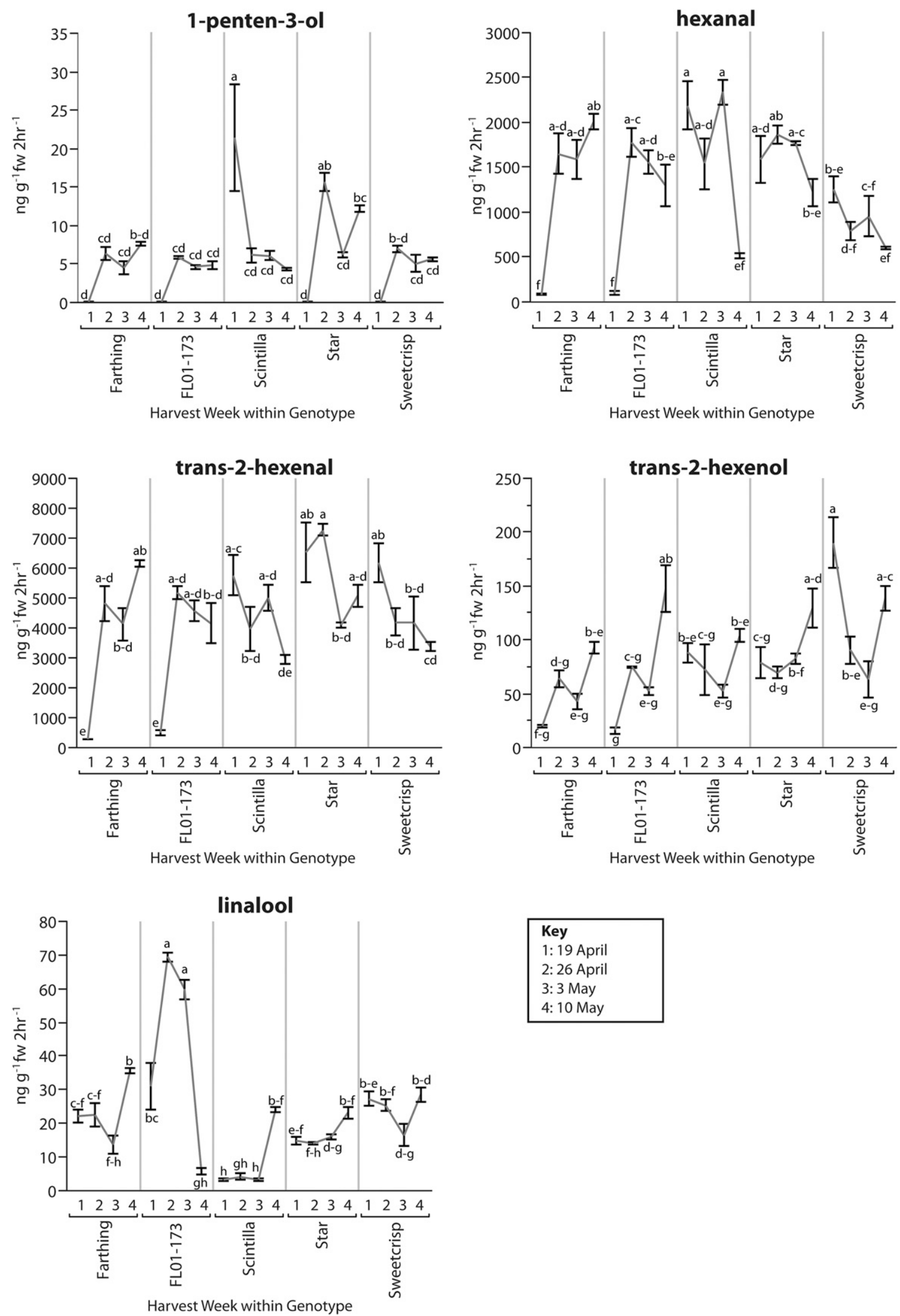

Fig. 6. Comparison of 1-penten-3-ol, hexanal, trans-2-hexenal, trans-2-hexenol, and linalool volatile profiles of five southern highbush blueberry cultivars collected at different harvest dates during the 2011 fruiting season. Each graph shows the amount of individual volatile compounds (ng. $\mathrm{g}^{-1} \mathrm{fresh}$ weight $/ 2 \mathrm{~h}$ ) detected in 'Farthing', 'FL01-173', 'Scintilla', 'Star', and 'Sweetcrisp' on 19 Apr. (1), 26 Apr. (2), 3 May (3), and 10 May (4). Volatile names are suggested based on gas chromatography coelution of chemical standards in conjunction with mass spectrometry. Each data point indicates the mean and sE of three replications. Mean separations (Tukey-Kramer) are denoted by lower-case letters. 
Table 2. cv of all mature fruit measurements per volatile (1-penten-3-ol, hexanal, trans-2-hexenal, trans-2hexenol, linalool) within five blueberry cultivars ('Farthing', 'FL01-173', 'Scintilla', 'Star', and 'Sweetcrisp').

\begin{tabular}{lccccr}
\hline & \multicolumn{5}{c}{ CV } \\
\cline { 2 - 6 } Cultivar & 1-penten-3-ol & Hexanal & Trans-2-hexenal & Trans-2-hexenol & Linalool \\
\hline Farthing & 68.067 & 60.857 & 61.711 & 54.278 & 38.280 \\
FL01-173 & 62.775 & 60.780 & 55.560 & 73.297 & 64.784 \\
Scintilla & 95.420 & 49.401 & 31.308 & 35.824 & 110.356 \\
Star & 74.326 & 21.645 & 26.567 & 33.874 & 24.493 \\
Sweetcrisp & 66.052 & 36.530 & 31.434 & 46.714 & 24.707 \\
\hline
\end{tabular}

Table 3. Genetic (genotype $=\mathrm{G}$ ), environment (harvest date within a season $=\mathrm{E}$ ), and $\mathrm{G} \times \mathrm{E}$ effects on volatile content in mature blueberry fruit.

\begin{tabular}{|c|c|c|c|}
\hline \multirow[b]{2}{*}{ Volatile compound } & \multicolumn{3}{|c|}{$P$ values } \\
\hline & G & $\mathrm{E}$ & $\mathrm{G} \times \mathrm{E}$ \\
\hline Cyclohexane & $<0.0001^{* * *}$ & $<0.0001^{* * *}$ & $<0.0001^{* * *}$ \\
\hline 2-methyl-2-butenal & 1 & $<0.0001^{* * *}$ & 0.2668 \\
\hline 1-penten-3-ol & $<0.0001^{* * *}$ & $0.0039 * *$ & $<0.0001 * * *$ \\
\hline 2-pentanone & 0.9789 & $<0.0001 * * *$ & 0.7351 \\
\hline 1-heptene & $<0.0001^{* * *}$ & $<0.0001^{* * *}$ & $0.0001 * * *$ \\
\hline 3-pentanone & 0.7809 & $<0.0001 * * *$ & $<0.0001 * * *$ \\
\hline 2-methyl butanal & 1 & $<0.0001 * * *$ & 0.0591 \\
\hline 2-ethyl furan & 1 & $<0.0001 * * *$ & $<0.0001^{* * *}$ \\
\hline 3,3-dimethyl butanone & 1 & $0.0012 * *$ & 0.2095 \\
\hline 2,4,4-trimethyl-1-pentene & 0.1411 & $<0.0001^{* * *}$ & 0.1836 \\
\hline 2-ethoxy-2-methyl butane & 1 & $<0.0001 * * *$ & 0.9242 \\
\hline 4-methyl-2-pentanone & 1 & $<0.0001 * * *$ & 0.7704 \\
\hline 3-methyl-2-pentanone, 2-methyl-3-pentanone & $<0.0001^{* * *}$ & $0.0245^{*}$ & $<0.0001 * * *$ \\
\hline 1-pentanol & 0.8819 & $<0.0001 * * *$ & 0.1115 \\
\hline (Z)-2-penten-1-ol & $<0.0001^{* * *}$ & $0.0001 * * *$ & $<0.0001 * * *$ \\
\hline Toluene & $0.0211^{*}$ & 0.9905 & 0.6169 \\
\hline 3-methyl butanoic acetate & $0.0113^{*}$ & $<0.0001 * * *$ & $<0.0001 * * *$ \\
\hline Hexanal & $<0.0001^{* * *}$ & $<0.0001 * * *$ & $<0.0001^{* * *}$ \\
\hline Trans-2-hexanal & $<0.0001^{* * *}$ & $0.0046^{* * *}$ & $<0.0001 * * *$ \\
\hline Trans-2-hexenol & $<0.0001^{* * *}$ & $<0.0001 * * *$ & $<0.0001 * * *$ \\
\hline 1-hexanol & $<0.0001^{* * *}$ & $0.0002 * * *$ & $<0.0001^{* * *}$ \\
\hline p-xylene & $<0.0001^{* * *}$ & 0.0611 & $0.0008^{* * *}$ \\
\hline 3-heptanone & $0.0262 *$ & $0.002 * *$ & 0.4263 \\
\hline 2-heptanone & 1 & $0.0008 * * *$ & $0.0006^{* * *}$ \\
\hline 1-nonene & 1 & $<0.0001 * * *$ & 0.4273 \\
\hline Nonane & 1 & 0.0924 & 0.3516 \\
\hline (E,E)-2,4-hexadienal & 0.9631 & $<0.0001 * * *$ & $0.0001 * * *$ \\
\hline 2-butyl-1-octanol & 1 & 0.0564 & 0.778 \\
\hline 4-methyl-1-heptene & 1 & $<0.0001 * * *$ & $0.027^{*}$ \\
\hline 6-methyl-2-heptanone & 0.4238 & 0.1932 & 0.1827 \\
\hline 2-ethyl-hexanal & $0.0005 * * *$ & $0.001 * *$ & $0.0346^{*}$ \\
\hline 1-ethyl-3-methyl benzene & $0.0002 * * *$ & $<0.0001 * * *$ & $0.0062 * *$ \\
\hline 1,2,3-trimethyl benzene & 0.9424 & $<0.0001 * * *$ & 0.98 \\
\hline 6-methyl-5-hepten-2-one & $<0.0001 * * *$ & $0.0352 *$ & 0.4065 \\
\hline 2-octane & $0.029^{*}$ & 0.1314 & 0.6922 \\
\hline Decane & $0.0056 * *$ & $0.0368 *$ & $0.017 *$ \\
\hline 2-octanone & 0.0814 & 0.783 & 0.0542 \\
\hline D-limonene & 0.0523 & $<0.0001 * * *$ & $<0.0001^{* * *}$ \\
\hline Eucalyptol & $0.0005 * *$ & $<0.0001 * * *$ & $0.001 * *$ \\
\hline 1,3 diethyl benzene & $0.0407 *$ & $<0.0001 * * *$ & $0.0063 * *$ \\
\hline 3-methyl decane & 0.7035 & $<0.0001 * * *$ & 0.1437 \\
\hline 1-methyl-2-(1-methylethyl) benzene & $0.0047 * *$ & $<0.0001^{* * *}$ & 0.0354 \\
\hline p-cimene & $0.0002 * * *$ & $0.0001 * * *$ & $0.0002 * * *$ \\
\hline Linalool & $<0.0001^{* * *}$ & $0.0001 * * *$ & $<0.0001 * * *$ \\
\hline Trans-2-undecen-1-ol & $<0.0001^{* * *}$ & $<0.0001 * * *$ & $0.0001^{* * *}$ \\
\hline
\end{tabular}

*,**,*** Significant at $P<0.05,0.01$, and 0.001 , respectively.

We attempted to minimize the potential impact of cultivar-specific harvest seasons by selecting fruit at similar stages of development. For example, although 'FL01-173' begins ripening at least 1 week before the other cultivars examined, a population of fruit of a similar developmental stage was available on all cultivars on a single harvest date. However, in the developmental measurements, 'FL01-173' and 'Farthing' did not reach the same levels of total volatiles as translocated per berry (Fig. 3D), more volatiles could be synthesized. This is in agreement with Chapman et al. (2004), who reported the intensity of vegetative and grassy aromas was inversely related to cropload. In our analyses, trans-2-hexenal and hexanal, two grassy-green volatiles, were the major contributors to total volatiles in all cultivars. It is also possible that trans-2-hexenal and hexanal were present in the 'FL01-173' and 'Farthing' fruit at this sampling point, but in a conjugated form that would have prevented its volatilization and, therefore, its collection (Bicalho et al., 2000).

We explored the effects of G, E, and the interaction effect of these two variables on volatile production (Table 3). In many cases, there was a significant variation as a result of the timing of harvest within a season (E). Some volatiles had exclusively non-genetic effects (just E), and many experienced a $\mathrm{G} \times$ $E$ effect. Toluene and 2-octane varied exclusively by G. P-xylene variation was the result of $\mathrm{G} \times \mathrm{E}$. Volatiles exhibiting strong $\mathrm{E}$ or $\mathrm{G} \times$ $E$ variability may prove to be difficult breeding goals. The existence of certain volatiles with only a $\mathrm{G}$ component is reassuring to breeders, who are likely unable to control $\mathrm{E}$ in field conditions. It appears that volatiles exhibit different gradations of $\mathrm{E}$ in different cultivars, which sets the stage for a broader survey of $\mathrm{G} \times \mathrm{E}$ effects on volatiles in blueberry germplasm. The estimates of genetic and environmental variability are limited in that this study was conducted over a single season. However, the extent of $\mathrm{E}$ variation in our data demonstrates the large role E may have within a single blueberry season.

In an attempt to quantify the variation over the harvests within each genotype, we calculated the $\mathrm{Cv}$ for the five volatiles examined in this article (Table 2) (CebollaCornejo et al., 2011). 'Star' had the smallest statistical variation in volatile content over the 4-week harvest period, whereas 'Scintilla' had the largest variation in volatile content. If these five volatiles are in fact the most important to the perception of blueberry flavor, then 'Star' may have the most consistent flavor in response to varying environmental factors. 'FL01-173' was very stable after the initial harvest date. Other than in the extremely variable 'Scintilla', linalool had very low Cvs in the other four cultivars. Unlike the other four volatiles, which are likely fatty acid catabolic products (Chen et al., 2004), linalool is a terpene alcohol known to be enzymatically produced in fruits and flowers (Tholl et al., 2011). Acetyl CoA from primary metabolism may enter two forks of volatile production pathways: an acetyl CoA molecule may enter fatty acid metabolism, whereupon a subset of fatty acids is catabolized to volatile compounds, or it may enter the mevalonate pathway, resulting in a range of terpenoid compounds. This latter and defined path to linalool may account for the minimized variation seen in its production in comparison with some of the fatty acid catabolic products. 
Typical breeding selection for blueberry flavor involves quantification of sugar and acid content, but identification of blueberry volatiles that correspond to the fruity, intense, sweet, and characteristic blueberry flavors could help blueberry breeders select for cultivars that produce a more desirable flavor. Because flavor is a complex trait, not only good fruit flavor, but consistent flavor throughout the harvest season is desirable.

\section{Literature Cited}

Almenar, E., H. Samsudin, R. Auras, and J. Harte. 2010. Consumer acceptance of fresh blueberries in bio-based packages. J. Sci. Food Agr. 90:1121-1128.

Baldwin, E.A., K. Goodner, and A. Plotto. 2008. Interaction of volatiles, sugars, and acids on perception of tomato aroma and flavor descriptors. J. Food Sci. 73:294-307.

Ballinger, W.E., L.J. Kushman, and J.F. Brooks. 1963. Influence of crop load and $\mathrm{N}$ applications on the yield and fruit quality of Wolcott blueberries. Proc. Amer. Soc. Hort. Sci. 82: 264-276.

Ballington, J.R., W.E. Ballinger, W.H. Swallow, G.J. Galletta, and L.J. Kushman. 1984. Fruit quality characterization of 11 Vaccinium species. J. Amer. Soc. Hort. Sci. 109:684-689.

Baloga, D.W., N. Vorsa, and L. Lawter. 1995. Dynamic headspace gas chromatography-mass spectrometry analysis of volatile flavor compounds from wild diploid blueberry species. ACS Symp. Ser. 596:235-247.

Beaudry, R. 1992. Blueberry quality characteristics and how they can be optimized. Annual Report of the Michigan State Horticultural Society 122:140-145.

Bicalho, B., A.S. Pereira, F.R. Aquino Neto, A.C. Pinto, and C.M. Rezende. 2000. Application of High-temperature gas chromatography-mass spectrometry to the investigation of glycosidically bound components related to cashew apple (Anacardium occidentale L.Var. nanum) volatiles. J. Agr. Food Chem. 48:1167-1174.

Bott, L. and E. Chambers, IV. 2006. Sensory characteristics of combinations potentially associated with beany aroma in foods. J. Sens. Stud. 21:308-321.

Cebolla-Cornejo, J., S. Roselló, M. Valcárcel, E. Serrano, J. Beltrán, and F. Nuez. 2011. Evaluation of genotype and environment effects on taste and aroma flavor components of Spanish fresh tomato varieties. J. Agr. Food Chem. 59: 2440-2450.

Chapman, D.M., M.A. Matthews, and J.X. Guinard. 2004. Sensory attributes of cabernet sauvignon wines made from vines with different crop yields. Amer. J. Enol. Viticult. 55:325-334.
Chen, G., R. Hackett, D. Walker, A. Taylor, Z. Lin, and D. Grierson. 2004. Identification of a specific isoform of tomato lipoxygenase (TomloxC) involved in the generation of fatty acid-derived flavor compounds. Plant Physiol. 136:26412651.

Dexter, R., A. Qualley, C.M. Kish, C.J. Ma, T. Koeduka, D.A. Nagegowda, N. Dudareva, E. Pichersky, and D. Clark. 2007. Characterization of a petunia acetyltransferase involved in the biosynthesis of the floral volatile isoeugenol. Plant J. 49:265-275.

Drake, M.A. and G.V. Ceville. 2003. Flavor lexicons. Compr. Rev. Food Sci. F. 2:33-40.

Du, X., A. Plotto, M. Song, J. Olmstead, and R. Rouseff. 2011. Volatile composition of four southern highbush blueberry cultivars and effect of growing location and harvest date. J. Agr. Food Chem. 59:8347-8357.

Fadanelli, L., M. Comai, A. Dorigoni, F. Mattivi, and A. Boschetti. 2005. Influence of crop load and production site on quality of 'Golden Delicious' apples during storage. Acta Hort. 682:749-756.

Galletta, G.J., W.E. Ballinger, R.J. Monroe, and L.J. Kushman. 1971. Relationships between fruit acidity and soluble solids levels of highbush blueberry clones and fruit keeping quality. J. Amer. Soc. Hort. Sci. 96:758-762.

Hirvi, T. and E. Honkanen. 1983. The aroma of blueberries. J. Sci. Food Agr. 34:992-998.

Hongsoongnern, P. and E. Chambers, IV. 2008. A lexicon for green odor or flavor and characteristics of chemicals associated with green. J. Sens. Stud. 23:205-211.

Horvat, R.J. and S.D. Senter. 1985. Comparison of volatile constituents from rabbiteye blueberries (Vaccinium ashei) during ripening. J. Food Sci. 50:429-431.

Kushman, L.J. and W.E. Ballinger. 1968. Acid and sugar changes during ripening in Wolcott blueberries. Proc. Amer. Soc. Hort. Sci. 92:290-295.

Lyrene, P. 2002. Development of highbush blueberry cultivars adapted to Florida. J. Amer. Pomol. Soc. 56:79-85.

Lyrene, P.M. 2005. Breeding low-chill blueberries and peaches for subtropical areas. HortScience 40:1947-1949.

Lyrene, P. 2008. Breeding southern highbush blueberries. Plant Breed. Rev. 30:353-414.

Lyrene, P.M. and W.B. Sherman. 1984. Breeding early-ripening blueberries for Florida. Proc. Fla. State Hort. Soc. 97:322-325.

Mattheis, J.P. and J.K. Fellman. 1999. Preharvest factors influencing flavor of fresh fruit and vegetables. Postharvest Biol. Technol. 15:227232

Moore, P.P., C. Burrows, J. Fellman, and D.S Mattinson. 2002. Genotype $\times$ environment variation in raspberry fruit aroma volatiles. Acta Hort. 585:511-516.
Parliament, T.H. and M.G. Kolor. 1975. Identification of the major volatile components of blueberry. J. Food Sci. 40:762-763.

Poll, L., A. Rindom, T.B. Toldam-Andersen, and P. Hansen. 1996. Availability of assimilates and formation of aroma compounds in apples as affected by the fruit/leaf ratio. Physiol. Plant. 97:223-227.

Saftner, R., J. Polashock, M. Ehlenfeldt, and B. Vinyard. 2008. Instrumental and sensory quality characteristics of blueberry fruit from twelve cultivars. Postharvest Biol. Technol. 49:19-26.

Sharpe, R.H. and G.H. Darrow. 1959. Breeding blueberries for the Florida climate. Proc. Fla. State Hort. Soc. p. 308-311.

Tholl, D., W. Boland, A. Hansel, F. Loreto, U.S.R. Röse, and J.P. Schnitzler. 2006. Practical approaches to plant volatile analysis. Plant J. 45: $540-560$

Tholl, D., R. Sohrabi, J.H. Huh, and S. Lee. 2011. The biochemistry of homoterpenes-Common constituents of floral and herbivore-induced plant volatile bouquets. Phytochemistry 72: 1635-1646.

Tieman, D., P. Bliss, L.M. McIntyre, A. BlandonUbeda, D. Bies, A.Z. Odabasi, G.R. Rodrigues, E. van der Knapp, M.G. Taylor, C. Goulet, M.H. Mageroy, D.J. Snyder, T. Colquhoun, H. Moskowitz, D.G. Clark, C. Sims, L. Bartoshuk, and H.J. Klee. 2012. The chemical interactions underlying tomato flavor preferences. Curr. Biol. 22:1035-1039.

Underwood, B.A., D.M. Tieman, K. Shibuya, R.J. Dexter, H.M. Loucas, A.J. Simkin, C.A. Sims, E.A. Schmelz, H.J. Klee, and D.G. Clark. 2005. Ethylene-regulated floral volatile synthesis in petunia corollas. Plant Physiol. 138: 255-266.

Vogel, J.T., D.M. Tieman, C.A. Sims, A.Z. Odabasi, D.G. Clark, and H.J. Klee. 2010. Carotenoid content impacts flavor acceptability in tomato (Solanum lycopersicum). J. Sci. Food Agr. 90: 2233-2240.

Williamson, J.G., F.S. Davies, and P.M. Lyrene. 2004. Pruning blueberry plants in Florida. 19 Mar. 2013. <http://edis.ifas.ufl.edu/hs223>.

Williamson, J.G., P.F. Harmon, O.E. Liburd, and P. Dittmar. 2013. 2013 Florida blueberry integrated pest management guide. 19 Mar. 2013. <http://edis.ifas.ufl.edu/hs380>.

Woodruff, R.E., D.H. Dewey, and H.M. Sell. 1960. Chemical changes of Jersey and Rubel blueberry fruit associated with ripening and deterioration. Proc. Amer. Soc. Hort. Sci. 75: 387-401.

Zhang, J., X. Wang, O. Yu, J. Tang, X. Gu, X. Wan, and C. Fang. 2010. Metabolic profiling of strawberry (Fragaria $\times$ ananassa Duch.) during fruit development and maturation. J. Expt. Bot. 62:1103-1118. 


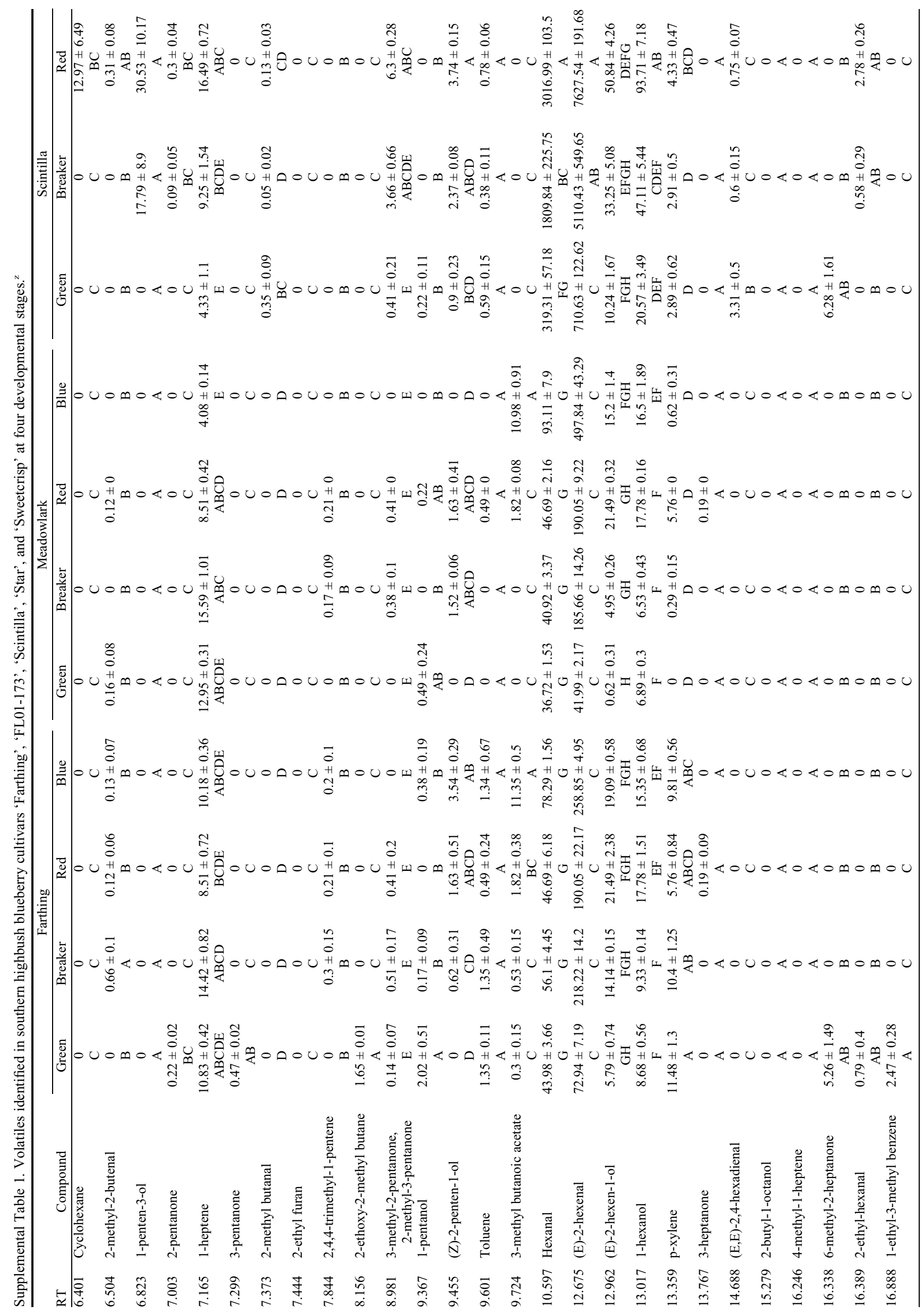

HortScience Vol. 48(7) July 2013 


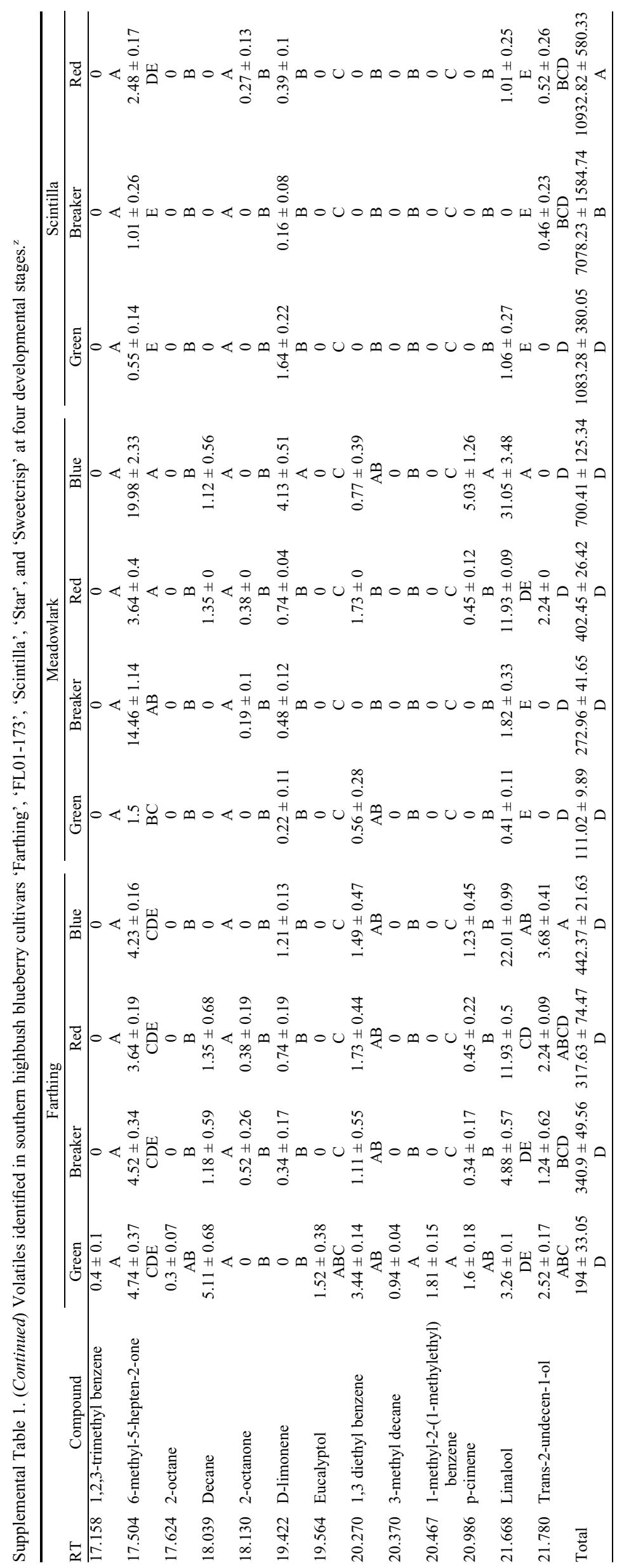




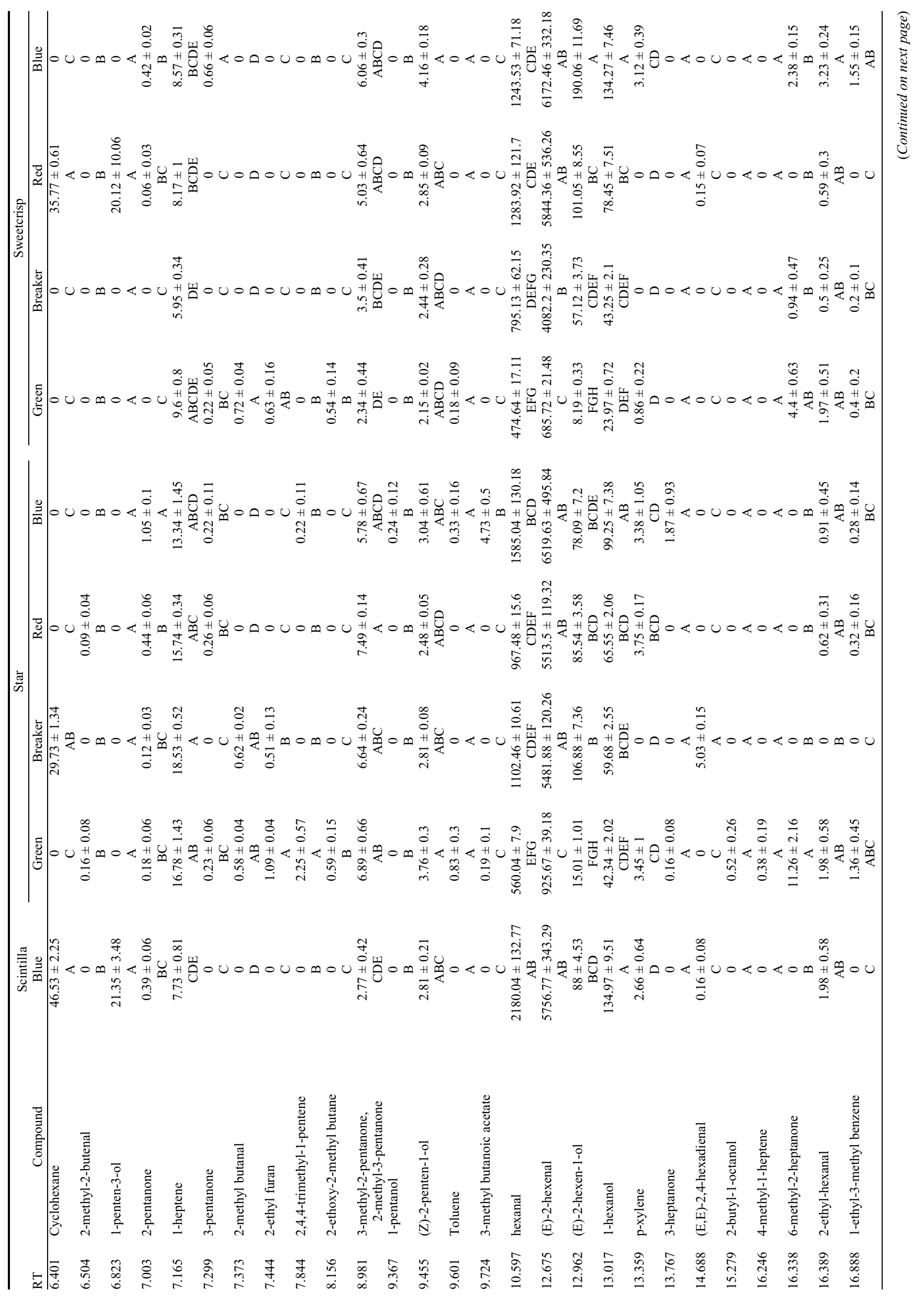




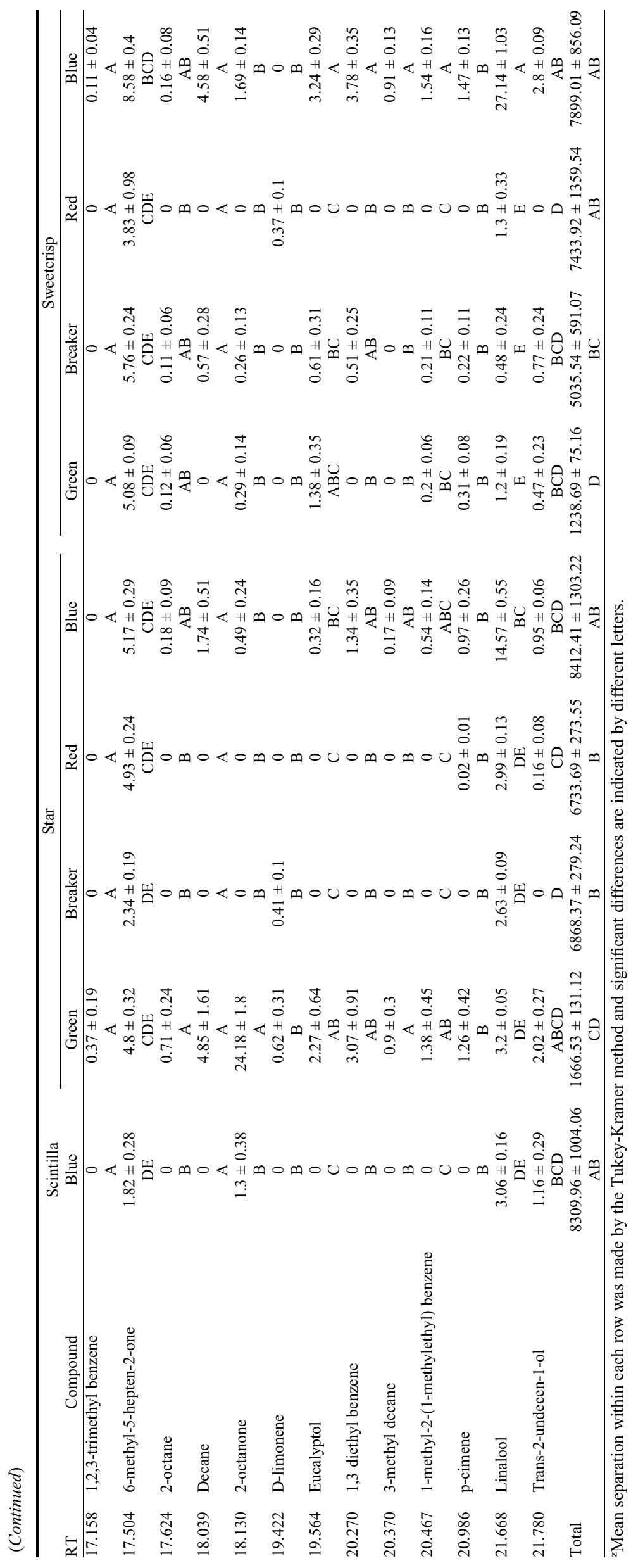




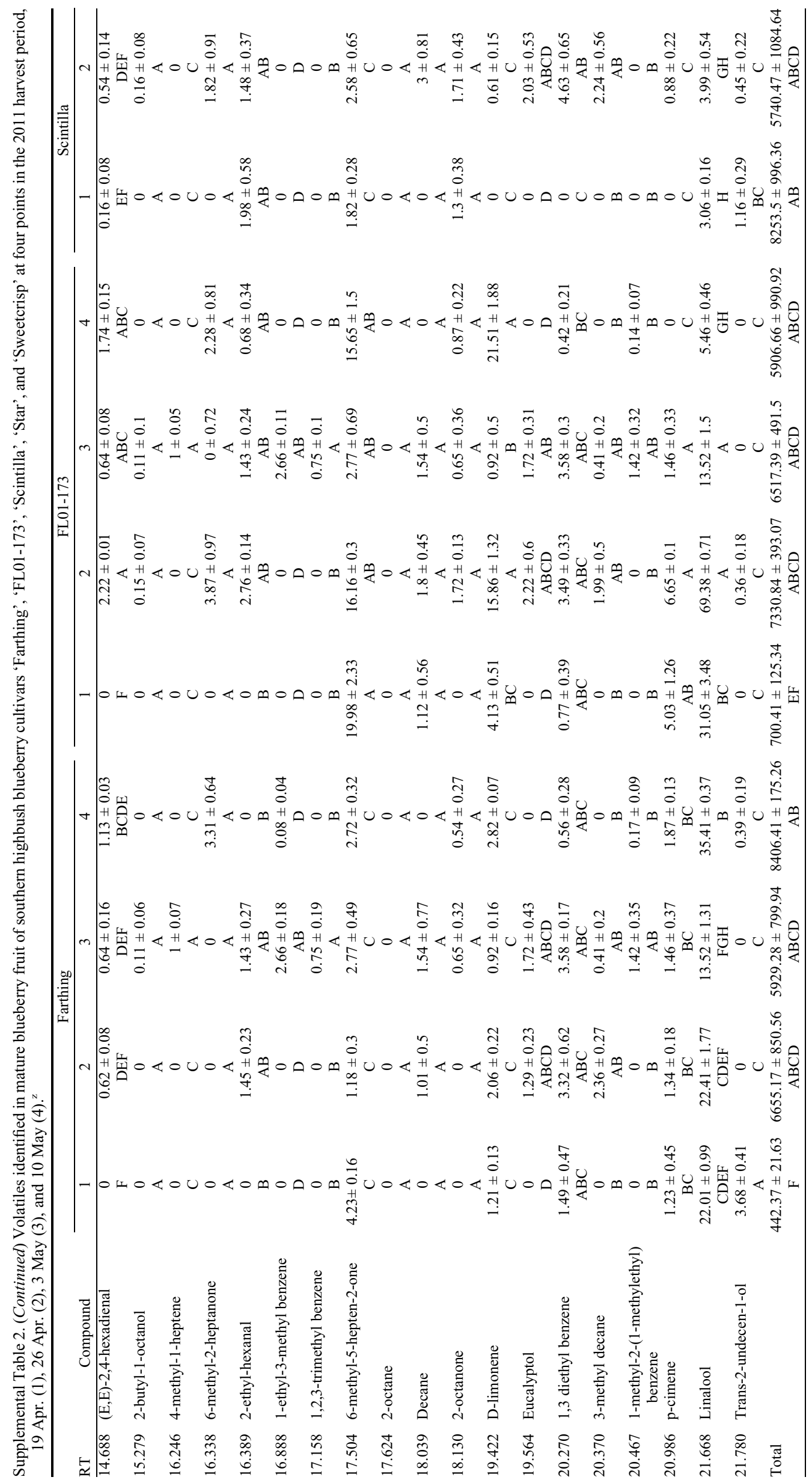




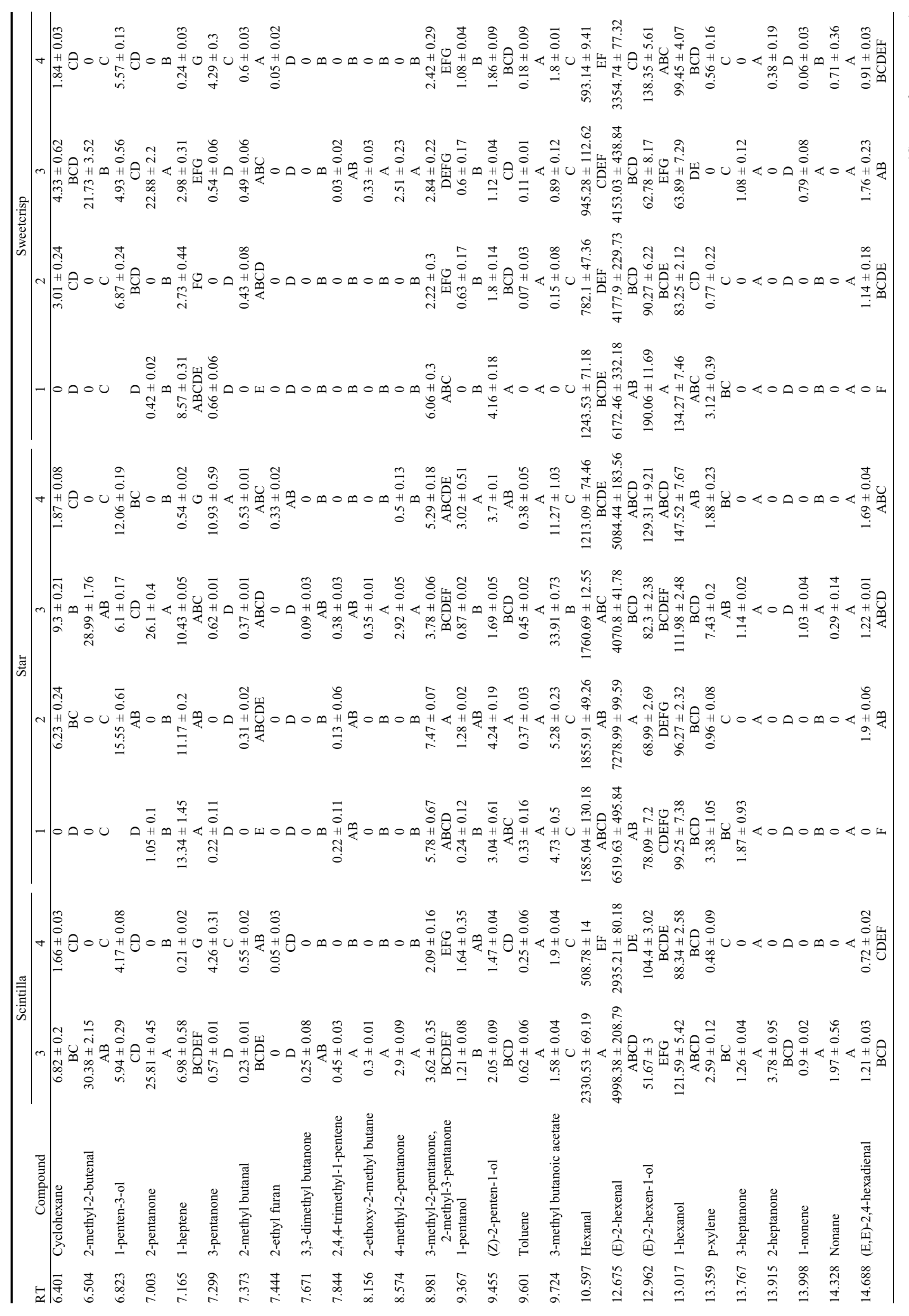




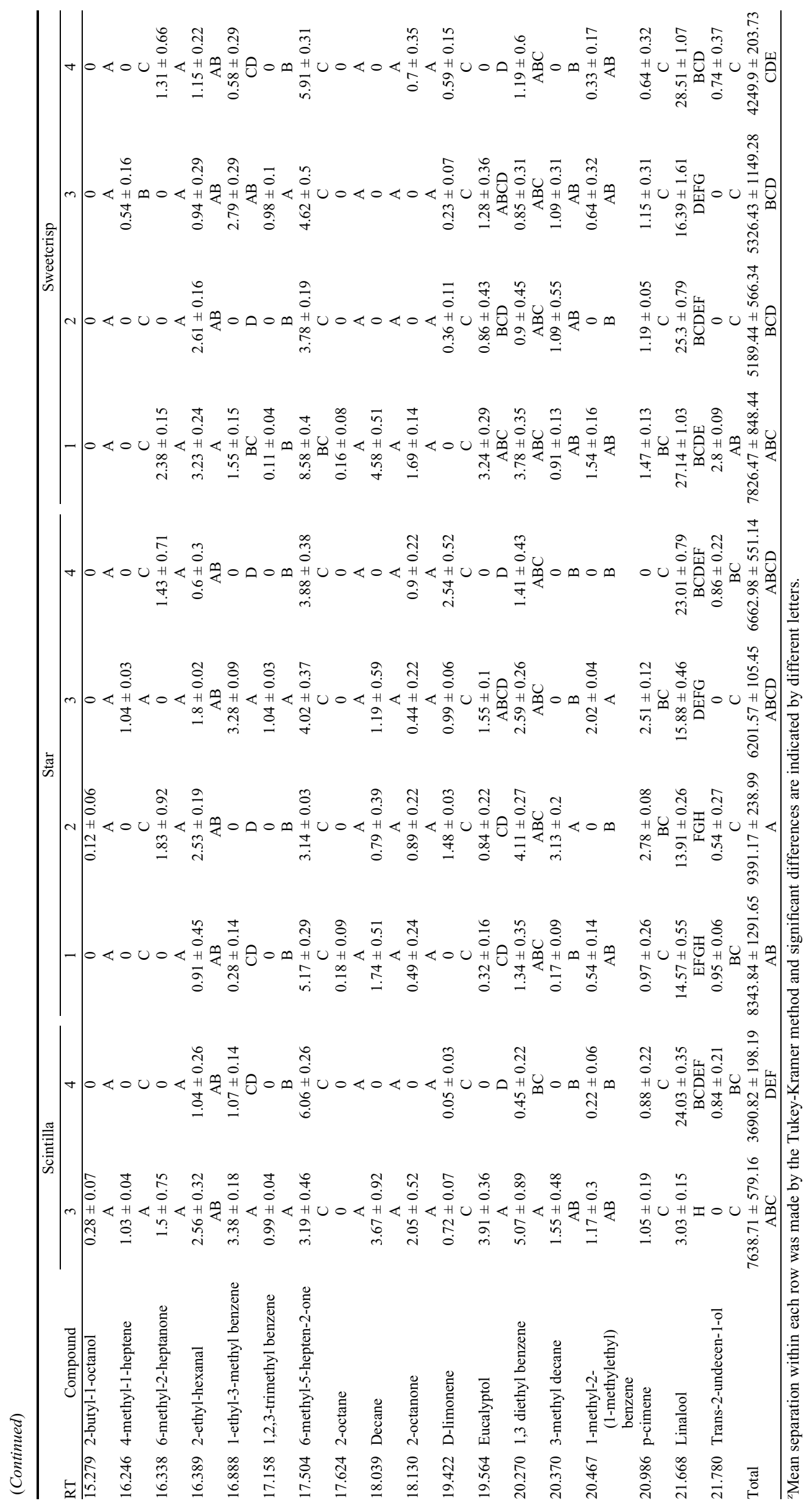

